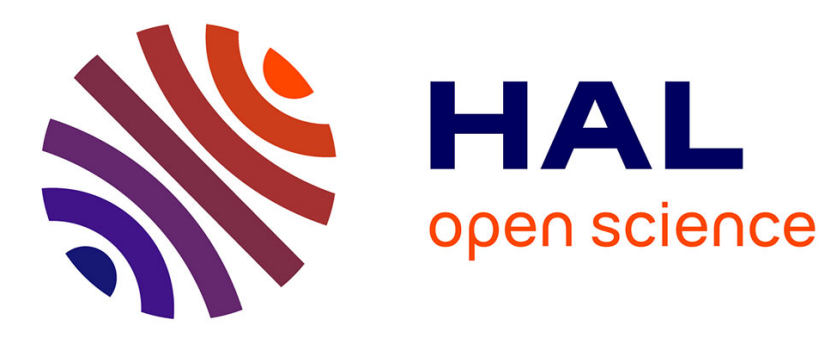

\title{
A Facile Access to New \\ Polymethylmethacrylate-Anchored Ferrocene Substituted Nickel(II) Unsymmetrical Schiff Base Complexes: Synthesis and Characterization.
}

Néstor Novoa, Juan Pablo Soto, Rodrigo Henríquez, Carolina Manzur, David Carrillo, Jean-René Hamon

\section{To cite this version:}

Néstor Novoa, Juan Pablo Soto, Rodrigo Henríquez, Carolina Manzur, David Carrillo, et al.. A Facile Access to New Polymethylmethacrylate-Anchored Ferrocene Substituted Nickel(II) Unsymmetrical Schiff Base Complexes: Synthesis and Characterization.. Journal of Inorganic and Organometallic Polymers and Materials, 2013, 23 (6), pp.1247-1254. 10.1007/s10904-013-9916-8 . hal-00915170

\author{
HAL Id: hal-00915170 \\ https://hal.science/hal-00915170
}

Submitted on 6 Dec 2013

HAL is a multi-disciplinary open access archive for the deposit and dissemination of scientific research documents, whether they are published or not. The documents may come from teaching and research institutions in France or abroad, or from public or private research centers.
L'archive ouverte pluridisciplinaire HAL, est destinée au dépôt et à la diffusion de documents scientifiques de niveau recherche, publiés ou non, émanant des établissements d'enseignement et de recherche français ou étrangers, des laboratoires publics ou privés. 
Submitted on July 10th 2013

Accepted on July 16th 2013

- DOI: $10.1007 / \mathrm{s} 10904-013-9916-8$

\title{
A Facile Access to New Polymethylmethacrylate-Anchored Ferrocene substituted Nickel(II) Unsymmetrical Schiff Base complexes: Synthesis and Characterization
}

\author{
Néstor Novoa ${ }^{\mathrm{a}}$, Juan Pablo Soto ${ }^{\mathrm{b}}$, Rodrigo Henríquez ${ }^{\mathrm{c}}$, \\ Carolina Manzur ${ }^{\mathrm{a}}$, David Carrillo ${ }^{\mathrm{a}}$, Jean-René Hamon ${ }^{\mathrm{d}}$,*
}

${ }^{a}$ Laboratorio de Química Inorgánica, ${ }^{b}$ Laboratorio de Polímeros, ${ }^{c}$ Laboratorio de Electroquímica, Instituto de Química, Facultad de Ciencias, Pontificia Universidad Católica de Valparaíso, Avenida Universidad 330, Curauma, Valparaíso, Chile

${ }^{d}$ UMR 6226 "Institut des Sciences Chimiques de Rennes”, CNRS-Université de Rennes 1, Campus de Beaulieu, 35042 Rennes Cedex, France

Corresponding authors. E-mail address: cmanzur@ucv.cl (C. Manzur); E-mail address: jeanrene.hamon@univ-rennes1.fr (J.-R. Hamon). 


\begin{abstract}
This paper discloses two new side-chain metallopolymers containing an unsymmetrical organometallic Schiff base complex of $\mathrm{Ni}$ (II) linked to a polymethylmethacrylate (PMMA) matrix. The neutral ferrocene substituted Schiff base complex 1, $\mathrm{Ni}\left\{\mathrm{CpFe}\left(\eta^{5}-\mathrm{C}_{5} \mathrm{H}_{4}\right)-\mathrm{C}(\mathrm{O}) \mathrm{CH}=\mathrm{C}\left(\mathrm{CH}_{3}\right) \mathrm{N}-o-\mathrm{C}_{6} \mathrm{H}_{4} \mathrm{~N}=\mathrm{CH}-\left(2-\mathrm{O}, 5-\mathrm{OH}-\mathrm{C}_{6} \mathrm{H}_{3}\right)\right\}$ where $\left(\mathrm{Cp}=\eta^{5}-\mathrm{C}_{5} \mathrm{H}_{5}\right)$, was synthesized via template reaction by condensation of the tridentate halfunit metalloligand $\mathrm{Fc}-\mathrm{C}(\mathrm{O}) \mathrm{CH}=\mathrm{C}\left(\mathrm{CH}_{3}\right)-\mathrm{N}(\mathrm{H})-o-\mathrm{C}_{6} \mathrm{H}_{4} \mathrm{NH}_{2}\left(\mathrm{Fc}=\right.$ ferrocenyl $\left.=\mathrm{CpFe}\left(\eta^{5}-\mathrm{C}_{5} \mathrm{H}_{4}\right)\right)$ with 2,5-dihidroxybenzaldehyde in the presence of Nickel(II) acetate tetrahydrate. The binuclear Schiff base complex of $\mathrm{Ni}(\mathrm{II})$ containing an aromatic free hydroxyl group was reacted under basic conditions with PMMA to afford, upon trans-esterification reaction, metallopolymers 2 (complex 1 monomeric unit / PMMA = 1/5) and $\mathbf{3}$ (complex 1 monomeric unit / PMMA = 1/3). Elemental analysis, FT-IR, ${ }^{1} \mathrm{H}$ and ${ }^{13} \mathrm{C}$ NMR spectroscopies, and cyclic voltammetry were utilized to characterize the newly synthetized compounds. Surface morphology of the metallopolymer film of $\mathbf{2}$ was studied using atomic force microscopy (AFM).
\end{abstract}

Keywords Schiff base complexes; metallopolymers; polymethylmethacrylate; atomic force microscopy; cyclic voltammetry 


\section{Introduction}

Interest in the preparation of Polymers incorporating metallic and semi-metallic subunits is continuously growing in light of their chemical and physical properties as well as their potential applications [1-6]. This mainly arises from the wide range of coordination numbers, oxidation states and geometries existing with transition elements that offer the possibility of accessing a large diversity of metal-containing polymeric materials with unusual conformational, mechanical, and morphological characteristics, including thermal- and/or photo-processible properties required for industrial applications [7]. Among transition metalbased polymers, polymeric Schiff base complexes are considered as a very important class of coordination compounds which have been extensively studied owing to their wide applications in many biological, clinical, analytical and industrial activities, in addition to their important roles in catalysis and organic synthesis, as well as in the fields of molecularbased magnets, enhanced electrical conductivity, and non-linear optics (NLO) materials. All those fascinating aspects, where the metallic moieties are either as a part of the main-chain or pendant unit to the polymeric chain, have given rise to a prodigious growth of published literature that has been reviewed several times [8-13].

Recently, much interest has been devoted to the immobilization of Schiff base ligands and their relevant transition metal complexes on different supports that may be a range of materials, including functionalized multi-wall carbon nanotubes [14,15], post-modified metalorganic frameworks (MOFs) [16], and functionalized mesoporous silica [17-19], for heterogenous catalytic oxidations and organic transformations. Polyoxometalates [20] as well as polymethacrylates and polystyrenes serve also as supports to prepare Schiff base complexes based polymers via several techniques. The polymer-anchored metal Schiff base complex can be synthetized by either (i) a radical polymerization between a pre-formed and adequately functionalised Schiff base complex and a methacrylate monomer [21], or (ii) the Schiff base ligand is first built up on the polymer matrix followed by the insertion of the metallic ion to form the desired polymer-anchored metal complex [22,23], or (iii) the preformed and functionalized Schiff base ligand is reacted with chloromethylated polystyrene to form the polymer-bound ligand that is then treated with the metal salt [24].

In this paper, we report on the synthesis of a new organometallic donor substituted Nickel(II) unsymmetrical Schiff base complex, Ni\{CpFe $\left(\eta^{5}-\mathrm{C}_{5} \mathrm{H}_{4}\right)-\mathrm{C}(\mathrm{O}) \mathrm{CH}=\mathrm{C}\left(\mathrm{CH}_{3}\right) \mathrm{N}-o-$ $\left.\mathrm{C}_{6} \mathrm{H}_{4} \mathrm{~N}=\mathrm{CH}-\left(2-\mathrm{O}, 5-\mathrm{OH}-\mathrm{C}_{6} \mathrm{H}_{3}\right)\right\}(1)$ where $\mathrm{Cp}=\eta^{5}-\mathrm{C}_{5} \mathrm{H}_{5}$, and on the direct linkage of a welldefined binuclear Schiff base complex to a polymethylmethacrylate (PMMA) matrix. The 
polymer-supported Ni(II) Schiff base complexes $\mathbf{2}$ and $\mathbf{3}$ are obtained upon transesterification reactions of the hydroxy-functionalized Schiff base complex 1 with PMMA, in the ratios : complex 1 monomeric unit/PMMA matrix of $1 / 5$ and 1/3, respectively. The newly synthetized compounds were characterized using analitycal and spectroscopic methods, whereas surface morphology of the metallopolymer film of $\mathbf{2}$ was studied using atomic force microscopy (AFM).

\section{Experimental}

\subsection{Materials and Methods}

Manipulations of air-sensitive compounds were performed under a dinitrogen atmosphere using standard Schlenk techniques. The solvents were dried and distilled according to standard procedures. $O$-phenylenediamine, 2,5-dihydroxobenzaldehyde, nickel(II) acetate tetrahydrate and potassium tert-butoxide were purchased from Aldrich and used without further purification. The organometallic tridentate metalloligand $\mathrm{CpFe}\left(\eta^{5}-\mathrm{C}_{5} \mathrm{H}_{4}\right)$ $\mathrm{C}(=\mathrm{O}) \mathrm{CH}=\mathrm{C}\left(\mathrm{CH}_{3}\right) \mathrm{NH}-o-\mathrm{C}_{6} \mathrm{H}_{4}-\mathrm{NH}_{2}$ [25] and the polymethylmethacrylate matrix [26] were synthesized using the procedures described in the literature.

\subsection{Characterizations}

Solid-state FT-IR spectra were recorded on a Perkin-Elmer, Model Spectrum One spectrophotometer, with $\mathrm{KBr}$ disks in the 4000 to $400 \mathrm{~cm}^{-1}$ range. The ${ }^{1} \mathrm{H}$ and ${ }^{13} \mathrm{C}$ NMR spectra were recorded at 400 and $100 \mathrm{MHz}$, respectively, with a Bruker AVIII 400 spectrometer at the Centre Régional de Mesures Physiques de l'Ouest (CRMPO, Rennes). All NMR spectra are reported in parts per million $(\mathrm{ppm}, \delta)$ relative to tetramethylsilane $\left(\mathrm{Me}_{4} \mathrm{Si}\right)$, with the residual solvent proton resonance and carbon resonances used as internal standards. Coupling constants $(J)$ are reported in Hertz $(\mathrm{Hz})$, and integrations are reported as number of protons. The following abbreviations are used to describe peak patterns: $s=$ singlet, $d=d o u b l e t$, $\mathrm{t}=$ triplet, $\mathrm{m}=$ multiplet, br=broad. ${ }^{1} \mathrm{H}$ and ${ }^{13} \mathrm{C}$ NMR chemical shift assignments are supported by data obtained from ${ }^{1} \mathrm{H}_{-}{ }^{1} \mathrm{H} \mathrm{COSY},{ }^{1} \mathrm{H}_{-}{ }^{13} \mathrm{C} \mathrm{HMQC}$, and ${ }^{1} \mathrm{H}_{-}{ }^{13} \mathrm{C}$ HMBC NMR experiments, and are given according to the numbering scheme of Chart 1. Cyclic voltammetry (CV) measurements were performed using a Radiometer Analytical model PGZ 100 all-in one potentiostat, using a conventional three-electrode cell. In this study, the working electrode was a carbon, the auxiliary electrode was a $\mathrm{Pt}$ wire, and a $\mathrm{Ag} / \mathrm{AgCl}$ reference electrode was utilized. The ferrocene/ferrocenium $\left(\mathrm{Fc} / \mathrm{Fc}^{+}\right)$couple was located at $E_{1 / 2}=0.458 \mathrm{~V}$, where $E_{1 / 2}$ was calculated from the average of the oxidation and reduction peak potentials. Microanalyses 
were conducted on a Thermo-FINNIGAN Flash EA 1112 CHNS/O analyzer by the Microanalytical Service of the CRMPO at the University of Rennes 1 (France). Melting points were determined in evacuated capillaries on a Kofler Bristoline melting point apparatus and were not corrected. To explore de surface modification and film thicknesses an Atomic Force Microscopy (AFM) Digital Instrument NanoScope IIIA Series was employed. The AFM images were obtained in the scanning "tapping" mode at scan rate of $10.0 \mu \mathrm{m} \mathrm{s}^{-1}$ with a $\mathrm{Z}$ limit scanner of $5.94 \mu \mathrm{m}$.

Chart 1 Labeling scheme used for NMR assignments of 1

2.3 Synthesis of organometallic Schiff base complex $\mathrm{Ni}\left[\mathrm{CpFe}\left(\eta^{5}-\mathrm{C}_{5} \mathrm{H}_{4}\right)-\mathrm{C}(\mathrm{O}) \mathrm{CH}=\mathrm{C}\left(\mathrm{CH}_{3}\right) \mathrm{N}\right.$ $\left.o-\mathrm{C}_{6} \mathrm{H}_{4} \mathrm{~N}=\mathrm{CH}-\left(2-\mathrm{O}, 5-\mathrm{OH}-\mathrm{C}_{6} \mathrm{H}_{3}\right)\right](\mathbf{1})$

To a Schlenk tube containing a stirred solution of the "half-unit" $\mathrm{CpFe}\left(\eta^{5}-\mathrm{C}_{5} \mathrm{H}_{4}\right)$ $\mathrm{C}(\mathrm{O}) \mathrm{CH}=\mathrm{C}\left(\mathrm{CH}_{3}\right) \mathrm{NH}-o-\mathrm{C}_{6} \mathrm{H}_{4}-\mathrm{NH}_{2}(400 \mathrm{mg}, 1.11 \mathrm{mmol})$ in ethanol $(30 \mathrm{~mL})$ was added a solution of 2,5-dihydroxobenzaldehyde $(153.3 \mathrm{mg}, 1.11 \mathrm{mmol})$ in ethanol $(5 \mathrm{~mL})$. The resulting solution was stirred for $15 \mathrm{~min}$ at room temperature (r. t.). A solution of nickel(II) acetate tetrahydrate $(553 \mathrm{mg}, 2.22 \mathrm{mmol})$ in ethanol $(10 \mathrm{~mL})$ was then added, and the resulting solution was refluxed for $6 \mathrm{~h}$. The mixture was allowed to cool to r.t. Evaporation of the solution to half of this volume under vacuum gave a dark red precipitate. The solid material was filtered off, washed with cold methanol $(3 \times 3 \mathrm{~mL})$ and diethyl ether $(3 \times 3 \mathrm{~mL})$, and dried in vacuo for $1 \mathrm{~h}$ to afford $410.6 \mathrm{mg}(0.72 \mathrm{mmol}, 65 \%$ yield $)$ of a dark red powder. Mp: $248{ }^{\circ} \mathrm{C}$. Anal.Calcd for $\mathrm{C}_{27} \mathrm{H}_{22} \mathrm{FeNiN}_{2} \mathrm{O}_{3} \cdot \mathrm{CH}_{3} \mathrm{OH}\left(569.06\right.$ g.mol $\left.{ }^{-1}\right): \mathrm{C}, 59.09 ; \mathrm{H}, 4.61 ; \mathrm{N}$, 4.92. Found: C, 58.80, H, 4.08; N, 5.24. FT-IR (KBr pellet, $\left.\mathrm{cm}^{-1}\right): 3255(\mathrm{w}) v(\mathrm{O}-\mathrm{H}), 3107(\mathrm{w})$ $v(\mathrm{C}-\mathrm{H}$ aryl), 2969-2920(w) $v(\mathrm{C}-\mathrm{H}$ alkyl), 1603(m) $v(\mathrm{C}=\mathrm{O}), v(\mathrm{C}=\mathrm{N})$ and/or $v(\mathrm{C}=\mathrm{C}), 1580(\mathrm{~s})$, 1518(s) $v(\mathrm{C}=\mathrm{O}), 1435(\mathrm{~m}) \delta(\mathrm{O}-\mathrm{H}) .{ }^{1} \mathrm{H}$ NMR (400 MHz, DMSO-d $) \delta 2.45\left(\mathrm{~s}, 3 \mathrm{H}, \mathrm{CH}_{3}\right), 4.19$ (s, 5H, $\mathrm{C}_{5} \mathrm{H}_{5}$ ), 4.43 (br s, $\left.2 \mathrm{H}, \mathrm{C}_{5} \mathrm{H}_{4}\right), 4.74$ (br s, $\left.2 \mathrm{H}, \mathrm{C}_{5} \mathrm{H}_{4}\right), 5.81(\mathrm{~s}, 1 \mathrm{H}, \mathrm{CH}=\mathrm{C}), 6.74\left(\mathrm{~d},{ }^{3} J_{\mathrm{H}, \mathrm{H}}\right.$ 
$=9.7 \mathrm{~Hz}, 1 \mathrm{H}, \mathrm{H}-3), 6.90\left(\mathrm{~d},{ }^{3} J_{\mathrm{H}, \mathrm{H}}=9.7 \mathrm{~Hz}, 1 \mathrm{H}, \mathrm{H}-4\right), 6.91(\mathrm{~s}, 1 \mathrm{H}, \mathrm{H}-6), 7.03\left(\mathrm{t},{ }^{3} J_{\mathrm{H}, \mathrm{H}}=7.5\right.$ $\mathrm{Hz}, 1 \mathrm{H}, \mathrm{H}-11), 7.10\left(\mathrm{t},{ }^{3} J_{\mathrm{H}, \mathrm{H}}=7.9 \mathrm{~Hz}, 1 \mathrm{H}, \mathrm{H}-10\right), 7.46\left(\mathrm{~d},{ }^{3} J_{\mathrm{H}, \mathrm{H}}=8.0 \mathrm{~Hz}, 1 \mathrm{H}, \mathrm{H}-9\right), 8.02(\mathrm{~d}$, $\left.{ }^{3} J_{\mathrm{H}, \mathrm{H}}=8.0 \mathrm{~Hz}, 1 \mathrm{H}, \mathrm{H}-12\right), 8.59(\mathrm{~s}, 1 \mathrm{H}, \mathrm{N}=\mathrm{CH}), 8.82(\mathrm{br} \mathrm{s}, 1 \mathrm{H}, \mathrm{OH}) \cdot{ }^{13} \mathrm{C}\left\{{ }^{1} \mathrm{H}\right\}$ NMR $(100$ MHz, DMSO- $\left.d_{6}\right) \delta 24.40\left(\mathrm{CH}_{3}\right), 68.28\left(\mathrm{C}_{\alpha} \mathrm{C}_{5} \mathrm{H}_{4}\right), 69.74\left(\mathrm{C}_{5} \mathrm{H}_{5}\right), 70.48\left(\mathrm{C}_{\beta} \mathrm{C}_{5} \mathrm{H}_{4}\right), 79.58\left(\mathrm{C}_{\text {ipso }}\right.$ $\left.\mathrm{C}_{5} \mathrm{H}_{4}\right), 102.19(\mathrm{CH}=\mathrm{C}), 114.52(\mathrm{C}-6), 115.49$ (C-12), 119.27 (C-1), 120.75 (C-3), 121.55 (C9), 122.90 (C-11), 125.94 (C-10), 126.12 (C-4), 142.19 (C-7), 144.07 (C-8), 146.12 (C-5), $153.18(\mathrm{~N}=\mathrm{CH}), 159.25(\mathrm{C}-2), 162.88(\mathrm{CH}=C), 178.81(\mathrm{C}=\mathrm{O})$.

\subsection{General Procedure for trans-esterification Reaction}

A Schlenk tube was charged with a magnetic stir bar, complex 1 (100 mg, 0.186 mmol), potassium tert-butoxide (31 mg, $0.279 \mathrm{mmol}$ ) and $1.5 \mathrm{~mL}$ of THF. After $15 \mathrm{~min}$ of stirring a dark purple precipitate was formed, the reaction mixture was vigorously stirred for 5h. Then, a solid sample of the polymethylmethacrylate (PMMA) matrix was slowly added. After 10 min of stirring, $2 \mathrm{~mL}$ of THF were added and the vigorous stirring was continued for $30 \mathrm{~min}$ while the resulting solution was refluxed overnight. The mixture was cooled to $\mathrm{r}$. $\mathrm{t}$. and evaporation of the solution to half of its volume under reduced pressure gave a precipitate that was filtered off, washed with cold THF ( $3 \times 3 \mathrm{~mL})$, diethyl ether $(2 \times 3 \mathrm{~mL})$, and dried in vacuo for $2 \mathrm{~h}$. The solid material was dissolved in $\mathrm{THF}$ at $35^{\circ} \mathrm{C}$, filtered off and the filtrate allowed to slowly evaporate.

\subsubsection{Synthesis of metallopolymer 2}

93 mg of PMMA (0.186 mmol ; complex 1 monomeric unit / PMMA = 1/5), dark red film, yield $=80 \mathrm{mg}$. Anal. Found: C, 52.70; H, 5.92; N, 1.60\%.

\subsubsection{Synthesis of metallopolymer 3}

$55.8 \mathrm{mg}$ of PMMA(0.112 mmol; complex 1 monomeric unit / PMMA = 1/3), dark red amorphous solid, yield = 50mg. Anal. Found: C, 42.91; H, 3.69; N, 2.63\%. 


\section{Results and Discussion}

\subsection{Synthesis and Characterization}

The neutral binuclear unsymmetrical Schiff base complex monomer 1 was prepared by a one-pot template procedure starting from the half-units metalloligand $\mathrm{CpFe}\left(\eta^{5}-\mathrm{C}_{5} \mathrm{H}_{4}\right)$ $\mathrm{C}(\mathrm{O}) \mathrm{CH}=\mathrm{C}\left(\mathrm{CH}_{3}\right) \mathrm{NH}-o-\mathrm{C}_{6} \mathrm{H}_{4}-\mathrm{NH}_{2}$ and equimolar amounts of 2,5-dihydroxobenzaldehyde and nickel(II) acetate tetrahydrate under mild conditions, as outlined in Scheme 1. This binuclear salphen-type complexes was targeted as scaffolds for the construction of donor-acceptor materials because of its simple structures with a potential single point of attachment, taking advantages of an efficient, straight forward and inexpensive method for the synthesis of Schiff base ligands and their subsequent transition metal complexes. Compound $\mathbf{1}$ was isolated in a reasonable good yield of $65 \%$ as an air and moisture insensitive, thermally stable microcrystalline powder, exhibiting a rather good solubility in dichloromethane, tetrahydrofuran (THF) and dimethylsulfoxyde (DMSO), but it is insoluble in alcohols, diethylether and hydrocarbons. Its composition and identity were deduced from satisfactory elemental analysis, FT-IR spectroscopy, and one- and two-dimensional NMR experiments (see Section 2.3).

Scheme 1 Synthesis of binuclear unsymmetrical Schiff base complex 1

The solid-state FT-IR spectrum of $\mathbf{1}$ presents a characteristic set of medium to strong intensity bands in the range $1603-1518 \mathrm{~cm}^{-1}$ attributed to the $v\left(\mathrm{C}^{\cdots} \mathrm{C}\right), v\left(\mathrm{C}^{\cdots} \mathrm{N}\right)$ and/or $v(\mathrm{C} \cdots \mathrm{O})$ stretching vibrations of the organic Schiff base skeleton. In addition, the spectrum shows a weak absorption band at $3255 \mathrm{~cm}^{-1}$ assigned to the $v(\mathrm{O}-\mathrm{H})$ stretching mode of the 5-hydroxy substituent of the salicylidene ring, but the stretching vibration observed at $3203 \mathrm{~cm}^{-1}$ in the 
FT-IR spectrum of the starting metalloligand[25] and assigned to the hydrogen bonded enamine $\mathrm{N}-\mathrm{H}$ group is lacking, indicating that the coordination takes place through the deprotonated nitrogen atom.

The ${ }^{1} \mathrm{H}$ NMR spectrum of compound $\mathbf{1}$ exhibits the expected resonance pattern consistent with the proposed structure [27-30]. The ferrocenyl enaminoketonate entity is clearly identified by its three sharp singlet resonances at 2.45, 4.19 and $5.81 \mathrm{ppm}$ (integral ratio 3:5:1), respectively, due to the methyl, the unsubstituted cyclopentadienyl ring and the pseudo-aromatic methine protons. The H-3, H-4 and $\mathrm{H}-6$ protons of the 5-hydroxysalicylidene ring (see Chart 1 for labelling scheme) appear as two doublets and one singlet at 6.74, 6.90 and $6.91 \mathrm{ppm}$ (integral ratio 1:1:1), respectively, while the azomethine and the hydroxy protons show up as the most downfield shifted signals of the spectrum at 8.59 and $8.82 \mathrm{ppm}$, respectively. On the other hand, the asymmetry of compound $\mathbf{1}$ is clearly reflected by the four distincts resonances of the $o$-phenylene bridge, in agreement with four magnetically nonequivalent protons of the aromatic ring. They appear as one doublet $(\mathrm{H}-9)$, two triplets $(\mathrm{H}-10$ and $\mathrm{H}-11)$ and one doublet (H-12) signal pattern in the ranges 7.03-8.02 ppm. Moreover, this unsymmetrical nature of $\mathbf{1}$ is confirmed by the 21 lines observed in its proton decoupled ${ }^{13} \mathrm{C}$ NMR spectrum (see Section 2.3 for the complete assignment). Specifically, the signal of the carbonyl group appearing at 178.81 ppm experienced a up-field shift of about 14 ppm upon complexation of the oxygen atom to the nickel center.

Metallopolymers 2 (complex 1 monomeric unit / PMMA ratio = 1/5) and $\mathbf{3}($ complex $\mathbf{1}$ monomeric unit $/$ PMMA ratio $=1 / 3$ ) were synthetized by reacting the in situ deprotonated form of the asymmetric Schiff base derivative 1 with polymethylmetacrylate matrix in THF, as depicted in Scheme 2. The metallopolymer 2 was obtained as red-wine thin films, suitable for direct AFM analyses, upon slow evaporation of its THF solution at room temperature. Compound 2 shows good solubility in dichloromethane and THF, but is insoluble in all other common solvents. It were characterized by elemental analysis, FT-IR spectroscopy and atomic force microscopy. By contrast, metallopolymer 3 was obtained as an amorphous solid under the same evaporation conditions and is, therefore, not a suitable material for AFM analysis. Nevertheless, compound $\mathbf{3}$ was characterized by elemental analysis and FT-IR spectroscopy. Metallopolymer $\mathbf{3}$ is poorly soluble in dichloromethane and THF and insoluble in other common organic solvents.

It is important to note that the polymer matrix was not completely trans-esterified, because the percentage of substitution is influenced by the bulkiness of the organometallicinorganic hybrid 1. As expected, the increase DEGREE of substitution in the matrix is a 
function of the ratio used in the trans-esterification reactions, a evidenced by the elemental analysis of the two metallopolymers, showing a doubling of the N/C ratio on passing from 2 $(\% \mathrm{~N} / \% \mathrm{C}=0.03)$ to $3(\% \mathrm{~N} / \% \mathrm{C}=0.05)$.

Scheme 2 Synthesis of polymer-anchored Schiff base complexes 2 and 3

The solid-state FT-IR spectral data (Figure 1 and Table 1) of both metallopolymers 2 and $\mathbf{3}$ (spectra 3 and 4) can be viewed as the sum of that of the polymer matrix (spectrum 1) and that of the asymmetric Schiff base complex 1 (spectrum 2) as they show both the characteristic band of the ester carbonyl group $\left(1728-1730 \mathrm{~cm}^{-1}\right)$ of the polymer matrix, and the vibrationals bands due to the organic Schiff base skeleton in the range $1605-1514 \mathrm{~cm}^{-1}$ for $v(\mathrm{C}=\mathrm{O}), v(\mathrm{C}=\mathrm{N})$ and/or $v(\mathrm{C}=\mathrm{C})$. In addition, the disappearance in the spectra of both $\mathbf{2}$ and $\mathbf{3}$ (spectra 3 and 4), of the stretching vibration of the terminal hydroxyl group of starting material $1\left(3255 \mathrm{~cm}^{-1}\right.$, spectrum 2$)$ indicated successful trans-esterification reactions.

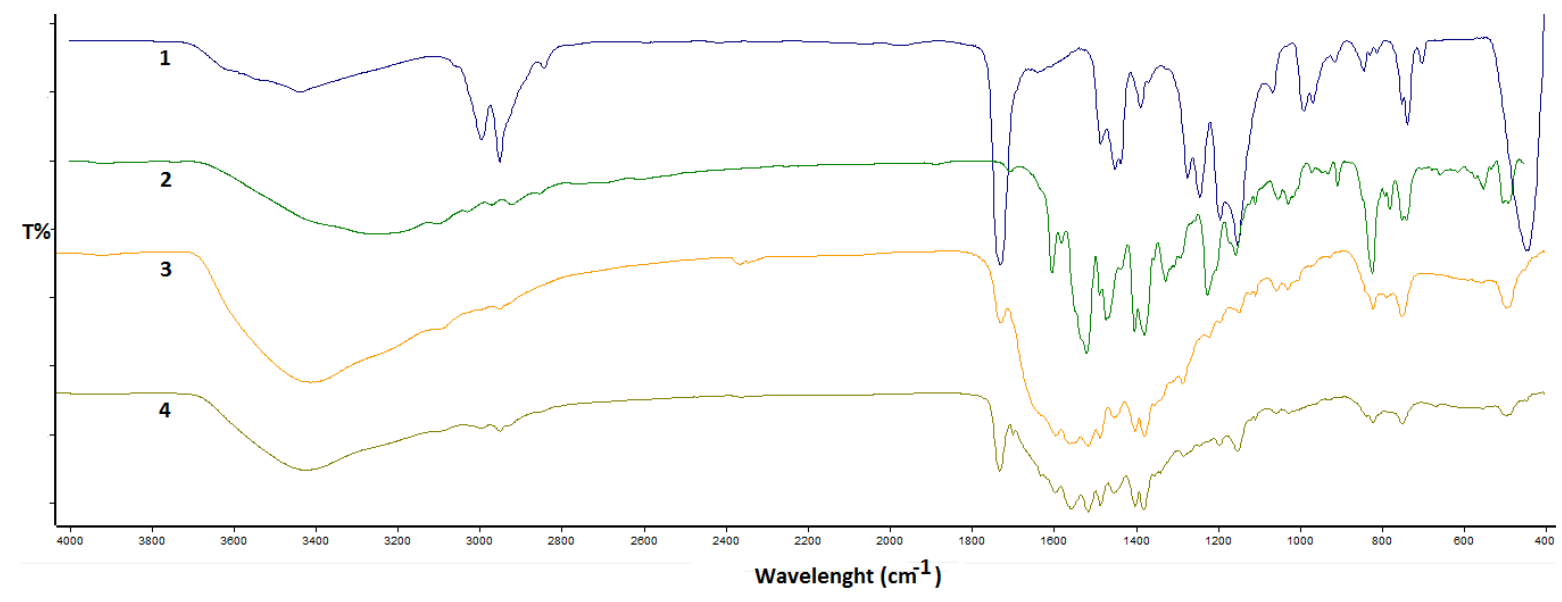


Fig. 1 Solid-state FT-IR spectras of plexiglass (blue, 1), Schiff base complex 1 (green, 2), Metallopolymer 2 (orange, 3), and Metallopolymer 3 (brown, 4).

Table 1 FT-IR spectral data of polymethylmethacrylate, complex 1, and metallopolymers 2 and $\mathbf{3}$

\begin{tabular}{|c|c|c|c|c|c|}
\hline \multirow{2}{*}{ Compounds } & \multicolumn{5}{|c|}{ Wave number $\left(\mathrm{cm}^{-1}\right)$} \\
\cline { 2 - 6 } & $v(\mathrm{O}-\mathrm{H})$ & $\begin{array}{c}v(\mathrm{C}=\mathrm{O}) \\
(\mathrm{ester})\end{array}$ & $v(\mathrm{C}-\mathrm{O}), v(\mathrm{C}-\mathrm{N})$ and/or $v(\mathrm{C}=\mathrm{C})$ & $v(\mathrm{C}-\mathrm{H}$ aryl $)$ & $v(\mathrm{C}-\mathrm{H}$ alkyl $)$ \\
\hline \multirow{2}{*}{ PPMA } & 3436 & 1730 & - & - & $2994-2950$ \\
\hline $\mathbf{1}$ & 3255 & - & $1603-1518$ & 3107 & $2969-2920$ \\
\hline $\mathbf{2}$ & 3412 & 1728 & $1605-1514$ (broad band $)$ & 3109 (broad band $)$ & 2986 \\
\hline $\mathbf{3}$ & 3420 & 1730 & $1698-1514$ & 3110 (broad band $)$ & 2994 \\
\hline
\end{tabular}

\subsection{Electrochemical study}

The electrochemical features of binuclear Schiff base Complex $\mathbf{1}$ and its polymerbound derivative 2 were investigated by cyclic voltammetry (CV) in dichloromethane solution containing $0.1 \mathrm{Mn} n-\mathrm{Bu}_{4} \mathrm{NPF}_{6}$ as supporting electrolyte. The $\mathrm{CV}$ of metallopolymer 3 could not be recorded owing to its lack of solubility. The CV measurements were carried out in $10^{-3} \mathrm{M}$ for the complex 1 and $10 \mathrm{mg}$ of the metallopolymer $\mathbf{2}$ in $10 \mathrm{~mL}$ of dichloromethane at room temperature in the potential range +1.5 to $-1.0 \mathrm{~V}$ with scan rate of $100 \mathrm{mV} \mathrm{s}^{-1}$. Cyclic voltammograms (Figures 2a and 2b) of solutions containing $\mathbf{1}$ and $\mathbf{2}$ show a chemically reversible oxidation process, due to the monoelectronic oxidation of the ferrocenyl moiety, with current ratio $i_{\mathrm{pa}} / i_{\mathrm{pc}}$ equal to unity, at $E_{1 / 2}=0.042$ and $0.032 \mathrm{~V} v s \mathrm{FcH} / \mathrm{FcH}^{+}$redox couple, and with anodic to cathodic peak-to-peak separations $\left(\Delta E_{\mathrm{p}}\right)$ of 84 and $64 \mathrm{mV}$, respectively. This increased difficulty to oxidize the Fe(II) center with respect to free ferrocene features the electron withdrawing ability of the neutral Schiff base side chain. Such CV data are in accordance with our previous observations within this family of binuclear macroacyclic unsymmetrical Schiff base complexes[30]. 


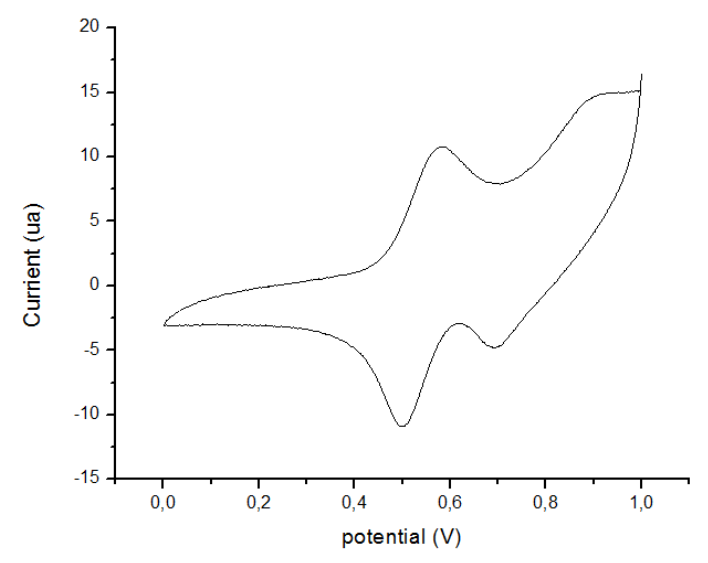

(a)

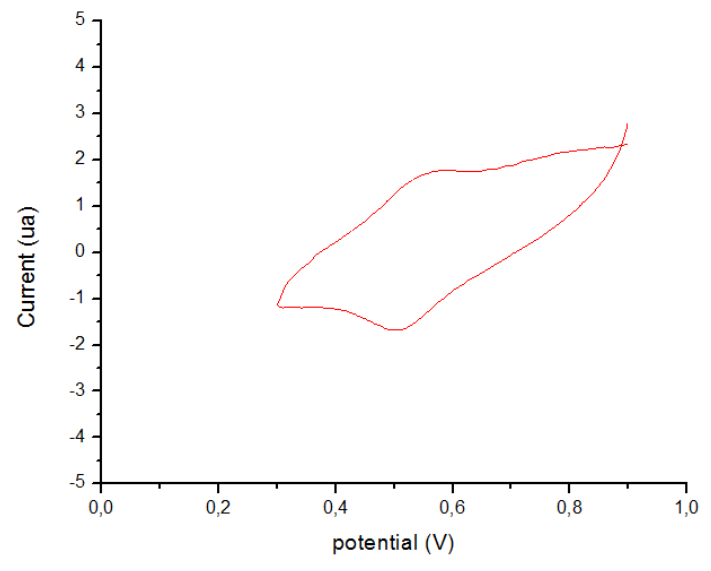

(b)

Fig. 2 Cyclic voltammograms of complex 1 (a) and of metallopolymer 2 (b), recorded in dichloromethane at $293 \mathrm{~K}$ on a vitreous carbon working electrode, with $0.1 \mathrm{M} n-\mathrm{Bu}_{4} \mathrm{~N}^{+} \mathrm{PF}_{6}{ }^{-}$as supporting electrolyte and scan rate $=0.1 \mathrm{Vs}^{-1}$.

Table 2. Electrochemical data for compounds $\mathbf{1}$ and $\mathbf{2}^{a}$

\begin{tabular}{|c|c|c|c|}
\hline Compound & $\mathrm{E}_{\mathrm{pc}} / \mathrm{V}$ & $\mathrm{E}_{1 / 2} / \mathrm{V}\left(\Delta \mathrm{E}^{b} / \mathrm{mV}\right)$ & $\mathrm{E}_{\mathrm{pa}} / \mathrm{V}$ \\
\hline $\mathbf{1}$ & - & $0.042(84)$ & $0.967^{c}$ \\
& & & $1.00^{d}$ \\
\hline $\mathbf{2}$ & - & $0.032(64)$ & - \\
\hline
\end{tabular}

${ }^{a}$ Recorder in dichloromethane at $293 \mathrm{~K}$ with a vitreous carbon working electrode, in $\mathrm{CH}_{2} \mathrm{Cl}_{2}$ solution containing $0.1 \mathrm{M} n-\mathrm{Bu}_{4} \mathrm{~N}^{+} \mathrm{PF}_{6}^{-}$as supporting electrolyte; all potential are vs. $\mathrm{Fc} / \mathrm{Fc}^{+}$ redox couple; scan rate $=0.1 \mathrm{Vs}^{-1} .{ }^{b}$ Peak-to-peak separation between the resolved reduction and oxidation wave maxima..$^{c}$ peak potential of the irreversible wave corresponding to $\mathrm{Ni}(\mathrm{II}) / \mathrm{Ni}(\mathrm{III})$ couple. ${ }^{d}$ Peak potential of the irreversible wave corresponding to [5-HO-sal]/[5$\mathrm{HO}$-sal] ${ }^{+}$couple.

Besides the reversible $\mathrm{Fe}(\mathrm{II}) / \mathrm{Fe}(\mathrm{III})$ redox process, the cyclovoltammogram of $\mathbf{1}$ displays also two irreversible oxidation waves at 0.967 and $1.000 \mathrm{~V}$, assigned to the $\mathrm{Ni}(\mathrm{II}) / \mathrm{Ni}(\mathrm{III})[28,30]$ and [5-HO-sal]/[5-HO-sal] $]^{+}[31]$ redox systems, respectively. Fast follow-up reactions such as precipitation, disproportionation or degradation of the electrogenerated unstable forms of the complex might explain the irreversibility of those redox processes. Such oxidation events are not observed in the CV of metallopolymer 2. As well, no reduction wave was present in cyclovoltammograms of both compounds $\mathbf{1}$ and $\mathbf{2}$. 


\subsection{Atomic Force Microscopy (AFM)}

In order to explore de surface modification of the PMMA matrix, AFM images were obtained for the films corresponding to the clean substrate and two independently prepared samples of metallopolymer 2 (Figure 3). The clean PMMA matrix presents a smooth morphology with homogeneous presence of pores as can be observed in Figure 3a. The pores observed in the surface have diameters of $250 \pm 80 \mathrm{~nm}$ and average pore density of $5.8 \pm 0.8$ pore/nm $\mathrm{nm}^{2}$. Thus, the base substrate exhibits a low surface roughness (RMS) and a roughness factor very close to one as can be observed in Table 2. These data indicate that the grain size mean (GSM) observed is representative of a compact surface. Upon grafting of the Schiff base complex 1, a marked change in the surface morphology can be found (see Figures $3 \mathrm{~b}$ and 3c). The formation of metallopolymer 2 onto the PMMA surface generates a homogeneous film that covers completely the base substrate. Moreover, this presents an irregular morphology composed of large agglomerations with cauliflower-like growth. In fact, this type of disorganized growth is completely consistent with a polymerization process characterized by rapid reaction kinetics. The quantitative data summarized in Table 2 indicate that as grown film causes a significant increase in RMS values and roughness factor compared to the base substrate finding an increase in $100 \%$ of the real surface area after the transesterification reaction. On the other hand the simple scotch tape test was performed to determine the thickness of the film. This test showed that under the experimental conditions the film has a thickness greater than $5.94 \mu \mathrm{m}$ which corresponds to the maximum $\mathrm{Z}$ scale of the scanner employed.

Table 2 Summary of morphological parameters obtained by AFM for the same samples shown in Figure 3.

\begin{tabular}{|c|c|c|c|c|}
\hline \multirow{2}{*}{ Compound } & \multicolumn{4}{|c|}{ AFM Parameters } \\
\cline { 2 - 5 } & $\begin{array}{c}\text { RMS } \\
\mathrm{nm}\end{array}$ & $\begin{array}{c}\text { GSM } \\
\mathrm{nm}^{2}\end{array}$ & $\begin{array}{c}\text { Roughness factor } \\
\text { a.u. }\end{array}$ & $\begin{array}{c}\text { Thickness } \\
\mu \mathrm{m}\end{array}$ \\
\hline & 3.11 & 381.4 & 1.0067 & - \\
\hline PMMA & 62.31 & 591.0 & 1.144 & $>5.94$ \\
\hline $\mathbf{2}$ (sample 1) & 69.94 & 665.2 & 1.112 & $>5.94$ \\
\hline
\end{tabular}


(a)

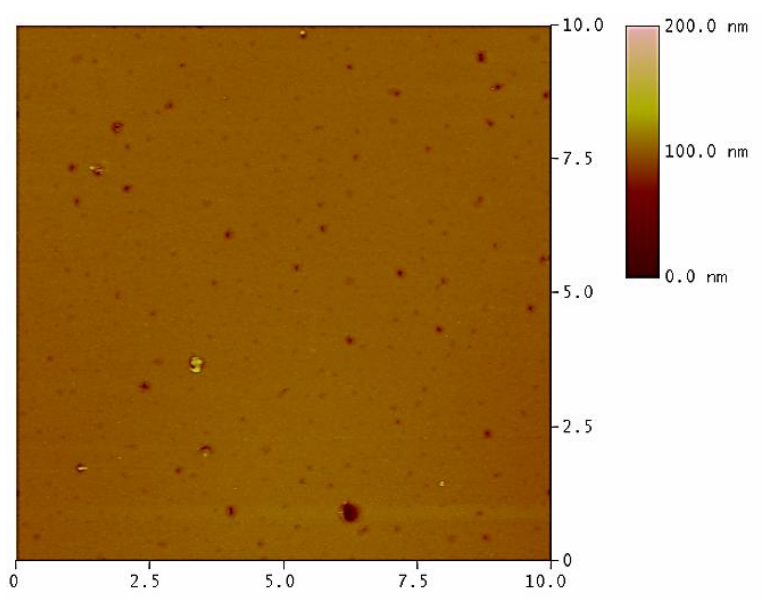

(b)

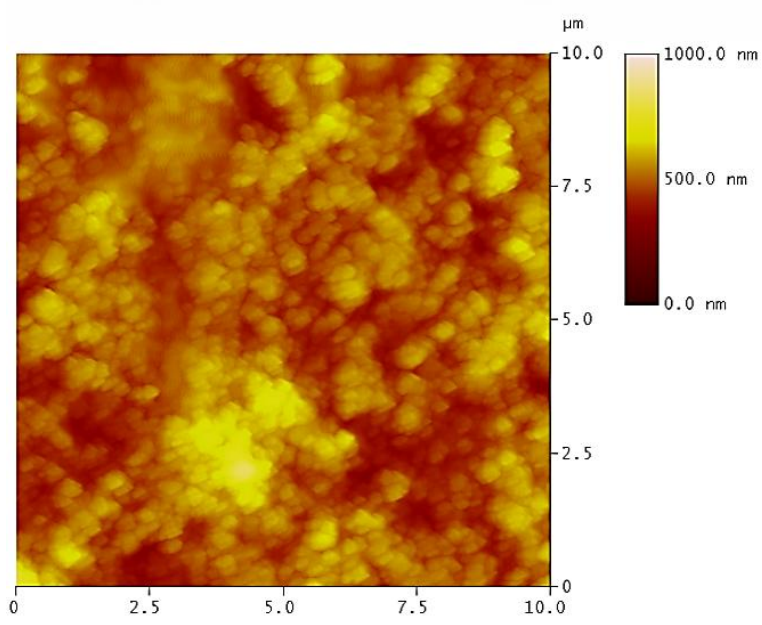

(c)

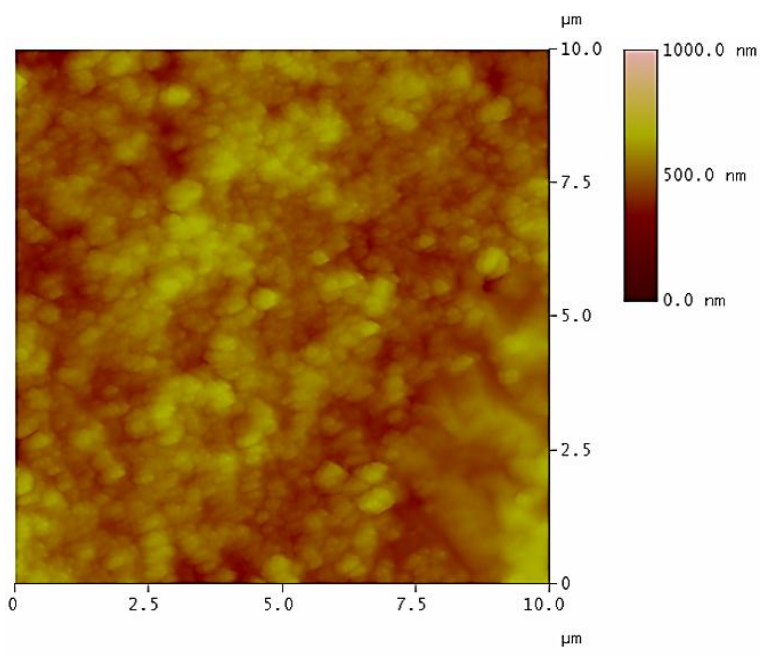

Fig. 3: AFM images obtained for: (a) starting PMMA matrix, (b) film of 2 (sample 1), and (c) film of 2 (sample 2). 


\section{Conclusion}

In summary, the prepared and fully characterized new nickel(II) complex of unsymmetrical dianionic quadridentate organometallic salen-type Schiff base was successfully grafted onto a polymethylmetacrylate matrix upon trans-esterification. The two obtained polymer-anchored Ni(II) Schiff base complexes were identified by elemental analysis, solid-state infrared spectroscopy and cyclic voltammetry. Moreover, the AFM images obtained show that the grafting of complex 1 onto the PMMA matrix generates a homogeneous film that presents a considerable growth in the real surface area and a classic cauliflowers type morphology. These synthesized new polymeric materials may be suitable for a range of novel applications, as for instance in optoelectronics, and thus will require greater exploration to improve their properties.

Acknowledgments The authors thank Dr S. Sinbandhit (CRMPO, Rennes) for NMR experiments. This research has been performed as part of the Chilean-French International Associated Laboratory for "'Inorganic Functional Materials"' (LIAMIF-CNRS N'836). Financial support from the Fondo Nacional de Desarrollo Científico y Tecnológico [FONDECYT (Chile), grant no. 1090310 (C.M. and D.C.)], the Vicerrectoría de Investigación y Estudios Avanzados, Pontificia Universidad Católica de Valparaíso, Chile (C.M. and D.C.), the CNRS and the Université de Rennes 1 is gratefully acknowledged. N.N. thanks the CONICYT (Chile) for support of a graduate fellowship. 


\section{References}

1. A.S. Abd-El-Aziz, C.E. Carraher, Jr., C.U. Pittman, Jr., J.E. Sheats, M. Zeldin, Macromolecules Containing Metal and Metal-Like Elements (Wiley-Interscience, New York, 2003)

2. I. Manners, Synthetic Metal Containing Polymers (Wiley VCH, Weinheim, 2004)

3. F. Ciardelli, E. Tsuchida, D. Worle, Macromolecules-Metal Complexes (Springer, Berlin, 1996)

4. P. Nguyen, P. Gomez-Elipe, I. Manners, Chem. Rev., 99, 1698 (1999)

5. A.S. Abd-El-Aziz, P.O. Shipman, B.N. Boden, W.S. McNeil, Prog. Polym. Sci., 35, 714 (2010)

6. A.S. Abd-El-Aziz, C.E. Carraher Jr., C. U. Pittman, Jr., M. Zeldin, Inorganic and Organometallic Macromolecules (Springer, New York, 2008)

7. A.S. Abd-El-Aziz, Encyclopedia of Polymer Science and Technology, 3rd edn. (WileyInterscience, New York, 2002)

8. K.C. Gupta, A. K. Sutar, C.-C. Lin, Coord. Chem. Rev., 253, 1926 (2009)

9. S. Kumar, D. Nath Dhar, P.N. Saxena, J. Sci. Indus. Res., 68, 181 (2009)

10. M. Verdaguer, A. Bleuzen, V. Marvaud, J. Vaissermann, M. Seuleiman, C. Desplanches, A. Scuiller, C. Train, R. Garde, G. Gelly, C. Lomenech, I. Rosenman, P. Veillet, C. Cartier, F. Villain, Coord. Chem. Rev., 190, 1023 (1999)

11. S. Di Bella, C. Dragonetti, M. Pizzotti, D. Roberto, F. Tessore, R. Ugo, Top. Organomet. Chem., 28, 1 (2010)

12. Y. Xin, J. Yuan, Polym. Chem., 3, 3045 (2012)

13. C.J. Whiteoak, G. Salassa, A.W. Kleij, Chem. Soc. Rev., 41, 622 (2012)

14. M. Salavati-Niasari, F. Davar, M. Bazarganipour, Dalton Trans., 39, 7330 (2010)

15. M. Salavati-Niasari, E. Esmaeili, H. Seyghalkar, M. Bazarganipour, Inorg. Chim. Acta, $375,11(2011)$

16. A.M. Shultz, A.A. Sarjeant, O.K. Farha, J.T. Hupp, S.T. Nguyen, J. Am. Chem. Soc., 133, $13252(2011)$

17. B.S. Rana, S.L. Jain, B. Singh, A. Bhaumik, B. Sain, A.K. Sinha, Dalton Trans., 39, 7760 (2010)

18. M. Nandi, P. Roy, H. Uyama, A. Bhaumik, Dalton Trans., 40, 12510 (2011)

19. S. Bhunia, S. Koner, Polyhedron, 30, 1857 (2011) 
20. M. Moghadam, V. Mirkhani, S. Tangestaninejad, I. Mohammadpoor-Baltork, M. Moshref Javadi, Polyhedron, 29, 648 (2010)

21. T. Suzuki, Y. Suzuki, K. Hachisu, H. Shinozaki, Polym. Adv. Technol., 22, 1278 (2011)

22. S.M. Islam, P. Mondal, S. Mukherjee, A.S. Roy, A. Bhaumik, Polym. Adv. Technol., 22, $933(2011)$

23. S.M. Islam, S. Paul, A.S. Roy, P. Mondal, J. Inorg. Organomet. Polym. Mater., 23, 560 (2013)

24. M.R. Maurya, A. Arya, A. Kumar, M.L. Kuznetsov, F. Avecilla, J. Costa Pessoa, Inorg. Chem., 49, 6586 (2010)

25. M. Fuentealba, A. Trujillo, J.-R. Hamon, D. Carrillo, C. Manzur, J. Mol. Struct., 881, 76 (2008)

26. J.A. Brydson, Plastics Materials, 7th edn. (Butterworth-Heinemann, Oxford, England, 1999), p. 398

27. M. Fuentealba, J.-R. Hamon, D. Carrillo, C. Manzur, New J. Chem., 31, 1815 (2007)

28. A. Trujillo, S. Sinbandhit, L. Toupet, D. Carrillo, C. Manzur, J.-R. Hamon, J. Inorg. Organomet. Polym. Mater., 18, 81 (2008)

29. A. Trujillo, M. Fuentealba, D. Carrillo, C. Manzur, J.-R. Hamon, J. Organomet. Chem., 694, 1435 (2009)

30. A. Trujillo, M. Fuentealba, D. Carrillo, C. Manzur, I. Ledoux-Rak, J.-R. Hamon, J.-Y. Saillard, Inorg. Chem., 49, 2750 (2010)

31. O. Hammerich, Organic Electrochemistry, 2nd Edn., M. Baizer, H. Lund (Eds.) (Marcel Dekker New York, Chapter 16, 1983) 